\title{
Thermal Conductivity and Frost Resistance of Foamed Concrete with Porous Aggregate
}

\author{
Eva Namsone, Genadijs Sahmenko, Elvija Namsone, Aleksandrs Korjakins \\ Riga Technical University, Faculty of Civil Engineering, Institute of Materials and Structures Address: Kipsalas \\ street 6a, Riga, LV-1048, Latvia
}

\begin{abstract}
The paper reports a study, which was carried out to examine thermal and frost resistance properties of foamed concrete (FC) with porous aggregate (expanded glass (EG) granules and cenospheres). By adding lightweight and porous aggregate to the FC mixture, it is possible to improve important physical, mechanical, and thermal properties of the prepared FC specimens. In the framework of this study the coefficient of thermal conductivity and frost resistance of hardened FC samples were determined. The structure of FC matrix and used aggregates were characterised by using a method of optical microscopy.
\end{abstract}

Keywords: porous aggregate, microstructure, foamed concrete, expanded glass, thermal conductivity.

\section{INTRODUCTION}

Construction industry in the total energy consumption is composed of forty per cent [1]. Growing costs of energy demand energy-efficient construction [2]. Engineering scientists are developing production of environmentally friendly building materials, such us foamed concrete (FC) [3].

Currently FC is regarded as very modern and widespread building material. It belongs to the group of lightweight concrete and is suitable for using in precast building elements as well as in monolithic structures [4].

The presence of considerable shrinkage is one of the main drawbacks of FC. This can be prevented by using a porous aggregate [5]. Physical properties of lightweight aggregates depend on the effect of moisture during the life cycle of a building material. Moisture influences characteristics of the respective building material, especially its durability properties. In porous materials drying rate is closely linked to their drying conditions [6]. For increasing durability it is necessary to obtain high water resistance.

The aim of this study is to analyse thermal and frost resistance properties of FC with porous aggregate.

\section{MATERIALS AND METHODS}

Used materials

All FC mixes were obtained experimentally in a laboratory setting. Intensive mixer (having a turbulence effect), foaming and pump functions was used. The following main components were used for preparation of FC mixes:

- Main binding agent - normal type Portland cement CEM I $42.5 \mathrm{~N}$. Compressive strength after 28 days is at least $42.5 \mathrm{MPa}$ and the specific surface is $3500-3900 \quad \mathrm{~cm}^{2} / \mathrm{g}$ (information provided by the producer, CEMEX, Ltd.).

- Filling component - natural, washed sand with fraction size $0 / 0.3 \mathrm{~mm}$. Sand also helps to promote the formation of foam. During the mixing the synthetic foaming agent was added.

- Pozzolanic additives - silica fume or microsilica (MS) and metakaolin (MK). MS usually has fine particles $(1 \mu \mathrm{m}-15 \mathrm{~nm})$ and it is useful as supplementary cementing material [7]. $\mathrm{MK}$ is a technogenic waste material, obtained from the manufacturing of expanded glass granules. It helps to improve workability and durability of concrete [8-9]. By using pozzolanic additives in the concrete mixture, the potential risk of alkali-silica reactions is reduced [10-13].

- Porous aggregate - expanded glass (EG) granules and cenospheres (CS). In this study cream-coloured EG granules (fraction size 4 to $8 \mathrm{~mm}$ ) were used. The pore structure with closed pores ensures low water absorption ability of EG granules (information provided by producer, JSC Stiklaporas). CS are obtained as a by-product from coal processing at the thermal power plants and have small diameters $(30-350 \mu \mathrm{m})$ but high strength $(20-100 \mathrm{MPa})$ [10].

In this study six experimental mixes of $\mathrm{FC}$ were produced. All of them were obtained with an average density class D800. EG granules were added in the mixes IP, IIP, IIIP. CS were used to obtain the mixes II, IIP, III, IIIP. Superplastifying admixture ('Stachema'), based on polycarboxylate was added in the mixes III and IIIP. Data and designations of all prepared FC mixes are summarized in Table 1.

ISSN 1691-5402

(C) Rezekne Academy of Technologies, Rezekne 2017 http://dx.doi.org/10.17770/etr2017vol3.2625 
Table 1.

Compositions of Prepared Fc Mixes

\begin{tabular}{|c|c|c|c|c|c|c|}
\hline & I & IP & II & IIP & III & IIIP \\
\hline $\begin{array}{l}\text { Portland cement } \\
\text { CEM I } 42.5 \mathrm{~N}\end{array}$ & + & + & + & + & + & + \\
\hline Sand $0 / 0.3 \mathrm{~mm}$ & + & + & - & - & - & - \\
\hline Water & + & + & + & + & + & + \\
\hline Foaming agent & + & + & + & + & + & + \\
\hline Cenospheres & - & - & + & + & + & + \\
\hline Metakaolin & + & + & + & + & + & + \\
\hline Microsilica & + & + & + & + & + & + \\
\hline $\begin{array}{l}\text { EG granules, } 4 \\
\text { to } 8 \mathrm{~mm}\end{array}$ & - & + & - & + & - & + \\
\hline PVA fibres & + & + & + & + & + & + \\
\hline Superplasticizer & - & - & - & - & + & + \\
\hline
\end{tabular}

Experimental procedure

The coefficient of thermal conductivity was determined by using heat flow measurement device 'Laser Comp's heat flow meter instrument FOX 600' (see Fig.1). Thermal conductivity test was performed according to EN 12667.

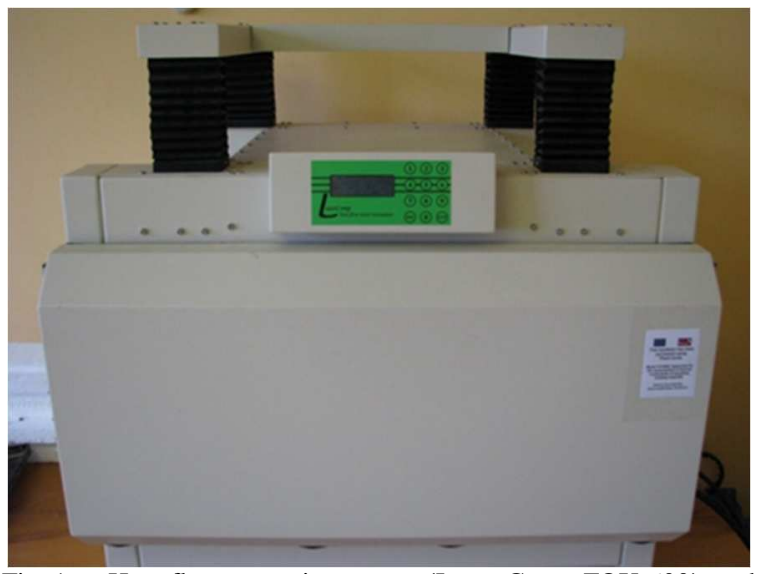

Fig. 1. Heat flow meter instrument 'Laser Comp FOX 600' used in the test of thermal conductivity

The operating principle of measuring equipment is based on the Bio - Fourier law, where the heat flow, the coefficient of thermal conductivity and temperature gradient are connected by the following Formula 1:

$$
q=-\lambda\left(\frac{d T}{d x}\right), \text { where: }
$$

$\mathrm{q}$ - heat flow that passes through the sample $\left(\mathrm{W} / \mathrm{m}^{2}\right)$; $\lambda$ - coefficient of thermal conductivity $(\mathrm{W} / \mathrm{mK})$; $\left(\frac{d T}{d x}\right)$ - temperature gradient of flat surface $(\mathrm{K} / \mathrm{m})$ [11].

The tested specimens were placed in this device between two metal plates with temperature difference $20^{\circ} \mathrm{C}$ (the bottom plate was the warm part $\left(+20^{\circ} \mathrm{C}\right)$ and the upper plate was the cold part $\left.\left(0^{\circ} \mathrm{C}\right)\right)$.

Frost resistance was tested according to LVS CEN/TS 12390-9. The tested specimens (cubes with dimensions $100 \times 100 \times 100 \mathrm{~mm}$, sawn in half) were partly immersed in water and then subjected to several freeze-thaw cycles. The samples were immersed in water at a depth of about $5 \mathrm{~mm}$, placing them face down in the containers. Under the tested surface of FC specimens $(5 \mathrm{~mm} \pm 0.1 \mathrm{~mm})$ spacers were placed, thereby ensuring uniform water layer beneath the concrete specimens.

If previously the same FC specimens have been used in the capillary water absorption test, the containers in this case must be sealed to prevent evaporation. Totally 14 cycles were applied to the tested specimens.

Freeze-thaw cycles were carried out in a climatic chamber 'Sunrise' by freezing to $-20^{\circ} \mathrm{C}$ and thawing at $+20^{\circ} \mathrm{C}$ (according to LVS CEN/TS 12390-9). After a certain number of cycles the specimens were visually inspected and additional frost resistance was determined by the quantity of crumbled particles in certain surface area $\left(\mathrm{g} / \mathrm{m}^{2}\right)$. The freeze-thaw cycle interval (accordingly to the above mentioned regulation) is presented in Fig. 2.

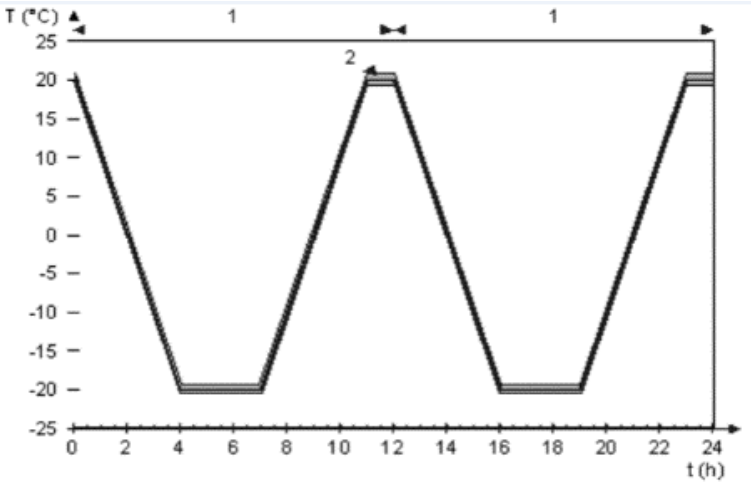

Fig. 2. Illustration of freezing-thawing cycles

Microstructure of the prepared FC mixes was investigated with the optical microscope VHX-2000 'Keyence Corporation'. The obtained images were used to determine the pore size (both of FC matrix and porous aggregate) with the computer software 'VHX2000 Analyzer'.

The test of compressive strength was performed according to LVS EN 12390-3. The specimens with standard dimensions $(100 \times 100 \times 100 \mathrm{~mm})$ were stored at the temperature $15^{\circ}-20^{\circ} \mathrm{C}$ and relative humidity level more than $90 \%$, and were tested at the age of 7 and 28 days.

\section{RESULTS AND DISCUSSION}

Thermal conductivity

FC specimens - plates with dimensions of $350 \mathrm{x}$ $350 \mathrm{~mm}$ (the thickness of slabs was determined by heat flow meter with an accuracy $0.01 \mathrm{~mm}$ ) were used for 
the thermal conductivity test. The results of the thermal test are summarized in Table 2.

Data about the thermal conductivity depending on the drying time (in days) are presented in a diagram (see Fig. 3). Till the age of 28 days, the prepared specimens were stored at the temperature $22^{\circ} \mathrm{C}$ and relative humidity $>90 \%$, but later the relative humidity was reduced to $50 \%$. According to the diagram, it can be seen that the coefficient of thermal conductivity tends to decrease over time. For example, the plate made from the FC composition II had about $18 \%$ lower thermal coefficient value (comparing measurements taken after 28 and 124 days of drying). The coefficient of thermal conductivity had lower values when all observed plates were in dryer condition than at the beginning of the test. This can be explained with the fact that the material with larger amount of water in its pores has higher thermal transmittance [12], so it resulted in higher values of thermal conductivity coefficient.

Table 2.

Results of Thermal Conductivity Test

\begin{tabular}{ccccc}
\multicolumn{5}{c}{ Results of Thermal Conductivity Test } \\
\hline $\begin{array}{c}\text { FC } \\
\text { compositio } \\
\text { n }\end{array}$ & $\begin{array}{c}\text { Drying } \\
\text { time } \\
\text { (days) }\end{array}$ & $\begin{array}{c}\text { The cofficient of thermal } \\
\text { conductivity } \\
\lambda \text { (x 1000) }\end{array}$ & $\begin{array}{c}\text { Average value } \\
\text { of } \lambda(\mathrm{W} / \mathrm{mK})\end{array}$ \\
\hline 1 & 2 & 7 & 8 & 9 \\
I & 28 & 133.91 & 138.86 & 0.136 \\
& 124 & 138.40 & 132.50 & 0.135 \\
I P & 28 & 122.90 & 121.09 & 0.122 \\
& 124 & 111.80 & 111.90 & 0.112 \\
II & 28 & 204.92 & 202.81 & 0.204 \\
& 124 & 172.86 & 173.09 & 0.173 \\
II P & 28 & 122.90 & 122.67 & 0.123 \\
& 124 & 108.41 & 108.29 & 0.108 \\
III & 28 & 254.64 & 246.93 & 0.251 \\
& 124 & 242.82 & 203.12 & 0.223 \\
III P & 28 & 151.46 & 151.78 & 0.152 \\
& 124 & 149.15 & 127.44 & 0.138 \\
\hline
\end{tabular}

The higher values of thermal conductivity coefficient after 124 days of hardening in in the laboratory setting (with the relative humidity level about $50 \%$ ) were obtained from plates prepared from I, II and III compositions $(0.135 \mathrm{~W} / \mathrm{mK}, 0.173 \mathrm{~W} / \mathrm{mK}$ and $0.223 \mathrm{~W} / \mathrm{mK}$ respectively). About $20.5 \%, 60.2 \%$ and $62 \%$ lower values of coefficient of thermal conductivity were gained from the plates made of IP, IIP and IIIP mixes $(0.112 \mathrm{~W} / \mathrm{mK}, 0.108 \mathrm{~W} / \mathrm{mK}$ and $0.138 \mathrm{~W} / \mathrm{mK}$ respectively) (see data of Fig. 3 and Table 2). This observation can be explained by the porosity of obtained FC specimens. Homogenous, porous composite concrete structure was obtained in compositions with EG granules and CS. By contrast, porosity of samples without porous aggregate was not so high. As it is known, the materials with high porosity level possess lower thermal conductivity coefficient values, because the heat in the material flows through both the pore walls and the pores of enclosed air.

The highest coefficient of thermal conductivity $(0.223 \mathrm{~W} / \mathrm{mK})$ after 124 days of curing was determined for the plate prepared from the composition III. During the mixing process, the superplasticizer was added in this composition. It created denser and less porous structure of the material. Comparing the specimens with porous aggregates, it can be seen that the higher value of thermal conductivity coefficient $(0.138 \mathrm{~W} / \mathrm{mK})$ is for the composition IIIP, it also has added chemical additive (superplasticiser).

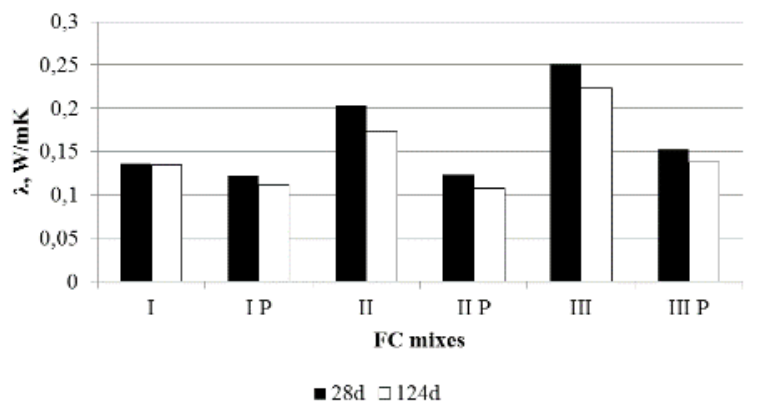

Fig. 3. Coefficient of thermal conductivity depending on the drying time (24 and 124 days)

Interaction of thermal conductivity and density

Thermal properties of concrete are closely connected with the moisture content in the structure of concrete; air has about 25 times lower thermal conductivity than water [17-18]. The thermal conductivity of concrete also depends on its density, cement content, mineralogy of the used aggregate, mineral admixture and temperature of concrete [19-22].

In summarizing the data about FC specimen coefficient of thermal conductivity and density, a graphic relationship is created (see Fig. 4, function in blue colour). It is clearly defined that thermal conductivity is a function of density [15]. Following the obtained graph, it can be seen that plates with lower density have lower thermal conductivity values and with higher density - higher values. Specimens with higher values of density (without light and porous aggregate) are less porous, but samples with lower density values (with granules of EG and CS) contain more cells or pores with enclosed air. Consequently, together with the reduced density and increased porosity of prepared specimens, the thermal properties of FC samples with lightweight and porous aggregate are improved.

There is a recommendation (see Formula 2) from ACI Committee 213R-03 (Guide for Structural Lightweight-Aggregate Concrete) [16] how to estimate the coefficient of thermal conductivity for the lightweight concrete:

$$
\lambda=0.0864 \cdot \mathrm{e}^{0.00125 \cdot \gamma},
$$


where:

$\lambda$ - the coefficient of thermal conductivity (W/mK); $\gamma$ - the density of lightweight concrete $\left(\mathrm{kg} / \mathrm{m}^{3}\right)$. The result of ACI formula is seen in Fig. 4 (function in red colour).

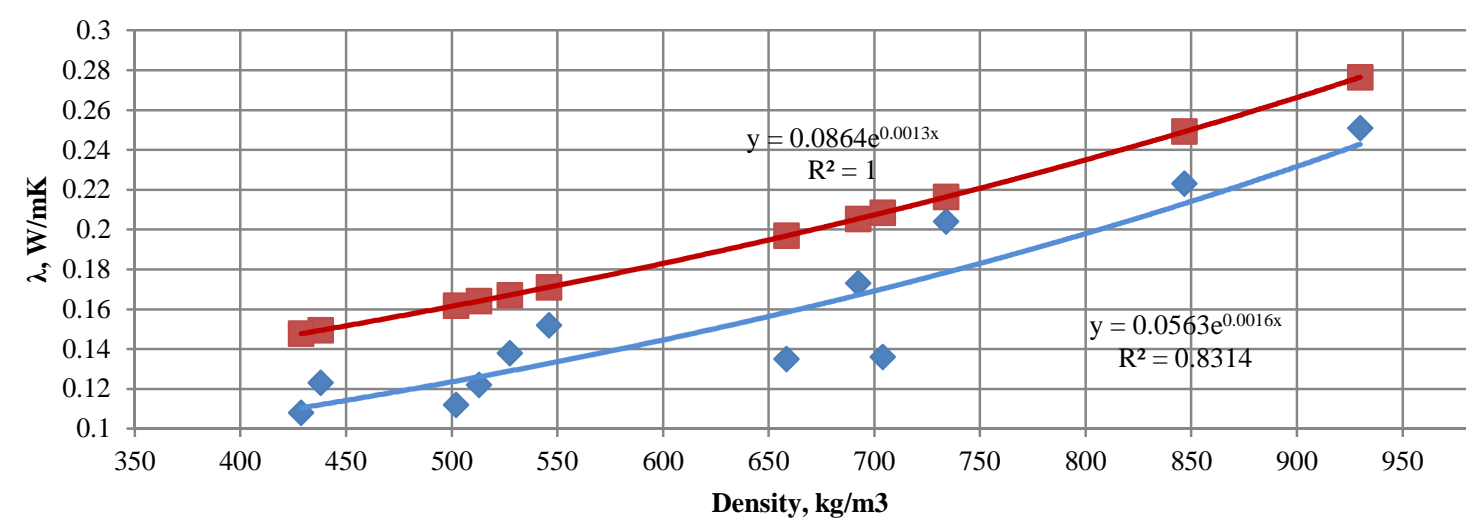

Experimental data $\quad$ ACI formula

Fig. 4. Interaction of thermal conductivity and density of FC

As can be seen in Fig. 4 and Formula (2), there is a strong relationship between the coefficient of thermal conductivity and the density of FC specimens $\left(\mathrm{R}^{2}=\right.$ 0.831 and $\mathrm{R}^{2}=1$ ). Analysing the results obtained experimentally and using a formula provided by ACI, it can be seen that both function graph have exponential tendency and the obtained functions are almost parallel. The values of thermal conductivity gained from the suggested equation are higher than experimentally obtained. The difference can be explained by the specifics of the formula provided by ACI; it is only relying on the density of concrete and does not take into account the volume of added aggregates (EG granules and CS). The comparison of experimental data and ACI formula data is included in Table 3.

Table 3.

Comparison of DATA: obtained experimentally VS using formula provided by aci

\begin{tabular}{|c|c|c|c|}
\hline $\begin{array}{c}\text { FC } \\
\text { composition }\end{array}$ & $\begin{array}{c}\text { Time } \\
\text { (days) }\end{array}$ & $\begin{array}{c}\text { Exp. obtained } \\
\text { value of } \lambda \\
(\mathrm{W} / \mathrm{mK})\end{array}$ & $\begin{array}{c}\text { ACI formula } \\
\text { proposed value of } \\
\lambda(\mathrm{W} / \mathrm{mK})\end{array}$ \\
\hline \multirow{2}{*}{1} & 2 & 3 & 4 \\
\hline \multirow{2}{*}{ I } & 28 & 0,136 & 0,208 \\
\cline { 2 - 4 } & 124 & 0,135 & 0,197 \\
\hline \multirow{2}{*}{ I P } & 28 & 0,122 & 0,164 \\
\cline { 2 - 4 } & 124 & 0,112 & 0,162 \\
\hline \multirow{2}{*}{ II } & 28 & 0,204 & 0,216 \\
\cline { 2 - 4 } & 124 & 0,173 & 0,205 \\
\hline \multirow{2}{*}{ II P } & 28 & 0,123 & 0,149 \\
\cline { 2 - 4 } & 124 & 0,108 & 0,148 \\
\hline \multirow{2}{*}{ III } & 28 & 0,251 & 0,277 \\
\cline { 2 - 4 } & 124 & 0,223 & 0,249 \\
\hline \multirow{2}{*}{ III P } & 28 & 0,152 & 0,171 \\
\cline { 2 - 4 } & 124 & 0,138 & 0,167 \\
\hline
\end{tabular}

\section{Frost resistance}

The results of frost resistance test are presented in Table 4 . The main parameter is an average weight loss of tested samples or quantity of crumbled particles during the freeze-thaw cycles.

Table 4.

Summary of obtained results - I

\begin{tabular}{|c|c|c|c|c|}
\hline FC mix & $\begin{array}{c}\text { Density } \\
\left(\mathrm{kg} / \mathrm{m}^{3}\right)\end{array}$ & $\begin{array}{c}\text { Compressive } \\
\text { strength, age of } \\
\text { 28 days (MPa) }\end{array}$ & $\begin{array}{c}\text { Average } \\
\text { weight } \\
\text { loss }(\mathrm{g})\end{array}$ & $\begin{array}{c}\text { Weight } \\
\text { loss } \\
\left(\mathrm{g} / \mathrm{m}^{2}\right)\end{array}$ \\
\hline 1 & 2 & 3 & 4 & 5 \\
\hline I & 736 & 2.5 & 0.6 & 60 \\
\hline IP & 565 & 1.4 & 1.3 & 130 \\
\hline II & 769 & 6.3 & 0.5 & 50 \\
\hline IIP & 445 & 2.5 & 1.1 & 110 \\
\hline III & 952 & 14.4 & 0.3 & 30 \\
\hline IIIP & 589 & 5.7 & 0.4 & 40 \\
\hline
\end{tabular}

From the obtained results it can be seen that specimens with higher density values have better frost resistance properties; the average weight loss is small (see Table 4). The samples prepared from mixes I, II and III showed the following values of weight loss: 60 $\mathrm{g} / \mathrm{m}^{2}, 50 \mathrm{~g} / \mathrm{m}^{2}$ and $30 \mathrm{~g} / \mathrm{m}^{2}$. The specimens from FC compositions IP, IIP and IIIP have more porous structure comparing to compositions I, II and III. Performance of these specimens in the tests was better as there was less pores and consequently water frozen inside the material damaged it less. Therefore, the values of weight loss from the FC compositions IP, IIP and IIIP were about $54 \%, 55 \%$ and $33 \%$ higher than I, II and III mixes. It can be explained by the use of light and porous aggregate (EG granules and CS) that made the structure less dense and more porous.

The specimens made from compositions III and IIIP had the lowest amount of damages; after 14 freezethaw cycles these specimens had almost none crumbled particle while in other specimens the process of scaling could be observed already after 14 cycles (see Fig. 5). 

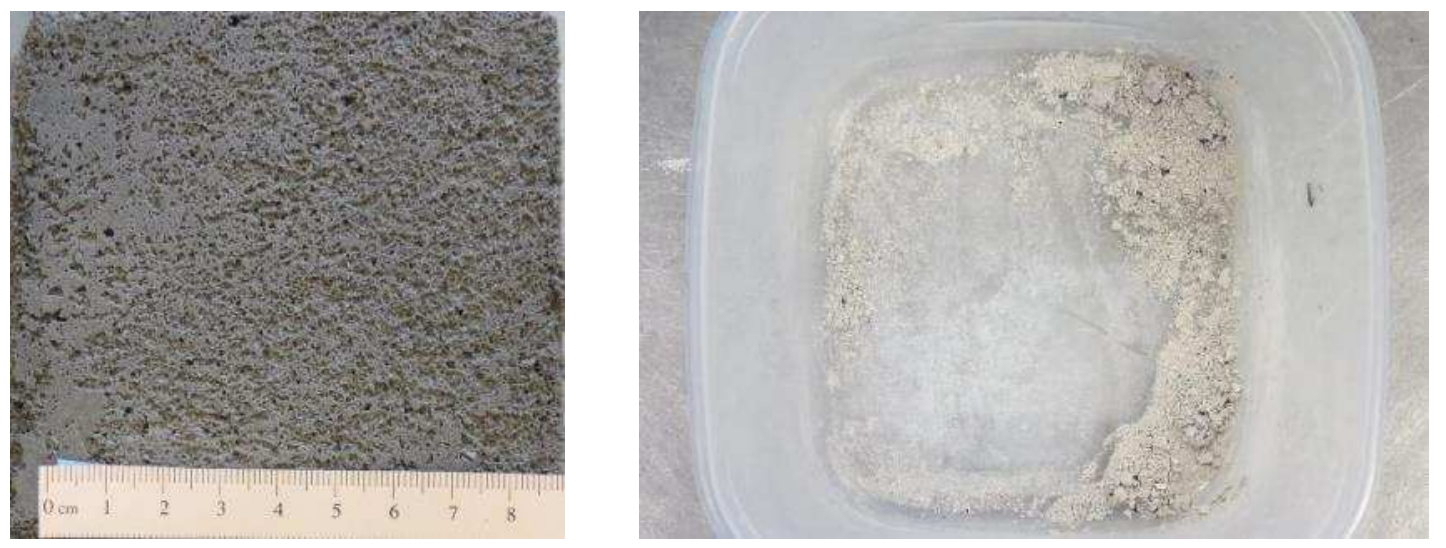

Fig. 5. FC (IP) after 14 cycles of freezing-thawing

The use of superplastifying additive in the FC mixes III and IIIP contributed to higher resistance of these specimens to freeze-thaw test. The structures of these specimens were denser compared to others and their pore size was smaller. It is very important to avoid capillary-sized pores because it decreases durability of the material.

Analysing the obtained data, it can be seen that higher values of compressive strength (at the age of 7 and 28 days) were for FC specimens, where porous aggregate were not included. Comparing the FC compositions I to II, it can be concluded that replacing the traditional quartz sand with CS gives a significant strength increase (up to $53.5 \%$ at the age of 7 days and up to $59.6 \%$ at the age of 28 days). The highest values of compressive strength $11 \mathrm{MPa}$ (at the age of 7 days) and 14.4 $\mathrm{MPa}$ (at the age of 28 days) were obtained testing the specimens prepared from the FC mix IIIP, which contained CS and superplasticizer contributing to a denser and less porous structure of the material. Among the compositions, where porous aggregate was used, the best results of compressive strength showed specimens from the FC mix IIIP (4.7 MPa at the age of 7 days and 5.7 $\mathrm{MPa}$ at the age of 28 days).

\section{Porosity and structure}

Microstructure of FC was studied in the crosssectional view of the material after sawing it with a diamond disc.

Analysing FC mixes with EG it can be concluded that lightweight aggregates are distributed uniformly over the cross-section without any processes of segregation. Examination of the FC mix IIIP showed that structure of pores of EG and matrix of FC cement is similar (see Fig. 6.). In the digital picture of microstructure can be seen that both (granules of EG and matrix of FC) have closed structure of pores, filled with air. This composition has homogeneous structure of pores that is ensure good thermal properties and capillary water absorption properties.

There is a risk of alkali-silica reactions on the contact area between matrix of FC cement and EG aggregate, when using amorphous silicates. Namely, use of the EG granules in cement-based composites can cause the reaction between amorphous silicon oxide and the alkali of cement. Consequently the volume of alkali silicate hydrogel can increase causing internal osmotic pressure, which results in the processes of concrete expansion and destroying of concrete structure. It may cause the deterioration of physico-mechanical properties and have negative impact on the longevity of concrete [4]. Therefore, special attention should be paid to this contact area. As shown in Fig. 6, contact area is relatively dense and there are no signs of deterioration.

Correlation between thermal conductivity and diameter of pores is presented in Fig. 7 and Table 5 . Compositions of FC (IP, IIP, IIIP) with lightweight aggregate had lower value of thermal conductivity.

Table 5 . Summary of obtained results - II

\begin{tabular}{|c|c|c|c|}
\hline FC mix & $\begin{array}{c}\text { Total } \\
\text { porosity, } \\
\%\end{array}$ & $\begin{array}{c}\text { Average } \\
\text { diameter } \\
\text { of pores, } \\
\mathrm{mm}\end{array}$ & $\begin{array}{c}\text { Average } \\
\text { value of } \lambda \\
(\mathrm{W} / \mathrm{mK})\end{array}$ \\
\hline 1 & 2 & 3 & 4 \\
\hline \multirow{2}{*}{ I } & \multirow{2}{*}{74.3} & \multirow{2}{*}{525.98} & 0.136 \\
\hline & & & 0.135 \\
\hline \multirow{2}{*}{ IP } & \multirow{2}{*}{80.2} & \multirow{2}{*}{521.02} & 0.122 \\
\hline & & & 0.112 \\
\hline \multirow{2}{*}{ II } & \multirow{2}{*}{73.1} & \multirow{2}{*}{552.16} & 0.204 \\
\hline & & & 0.173 \\
\hline \multirow{2}{*}{ IIP } & \multirow{2}{*}{84.4} & \multirow{2}{*}{500.42} & 0.123 \\
\hline & & & 0.108 \\
\hline \multirow{2}{*}{ III } & \multirow{2}{*}{66.7} & \multirow{2}{*}{382.18} & 0.251 \\
\hline & & & 0.223 \\
\hline \multirow{2}{*}{ IIIP } & \multirow{2}{*}{79.4} & \multirow{2}{*}{560.88} & 0.152 \\
\hline & & & 0.138 \\
\hline
\end{tabular}



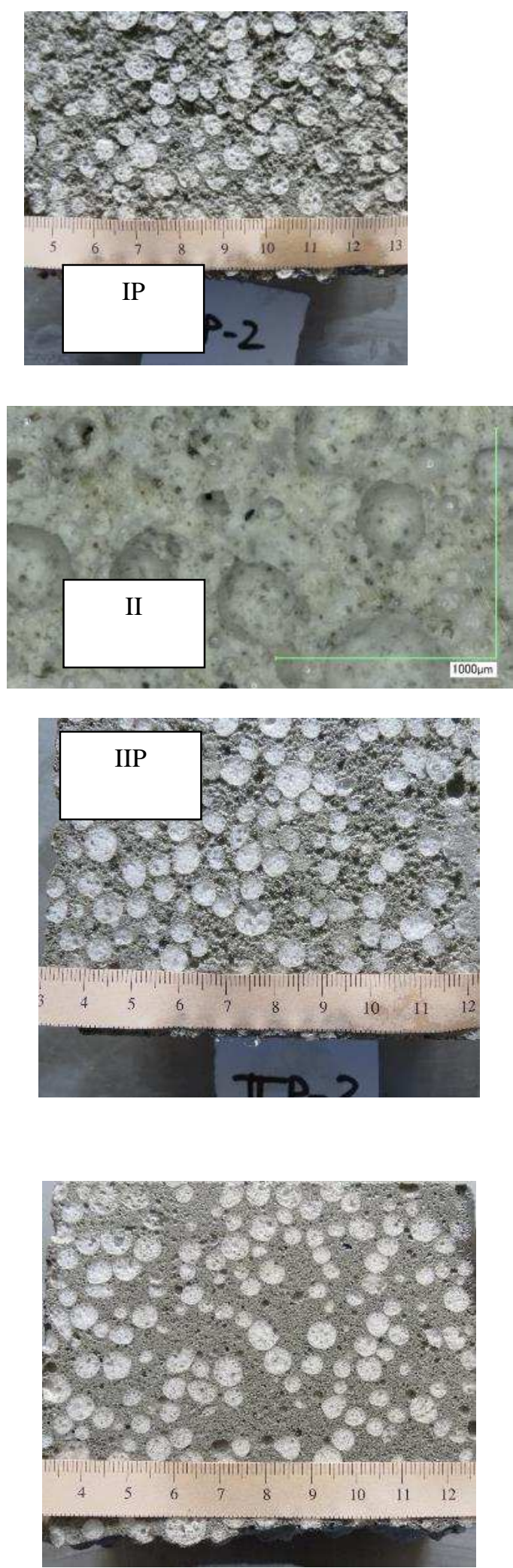

Fig. 6. Macro- and micro- structures of cross-section of FC.

Total porosity of FC mixes increases by adding porous aggregate up to $7.9 \%$ in the IP mix and up to $19 \%$ in the IIIP mix. Increase of total porosity for the
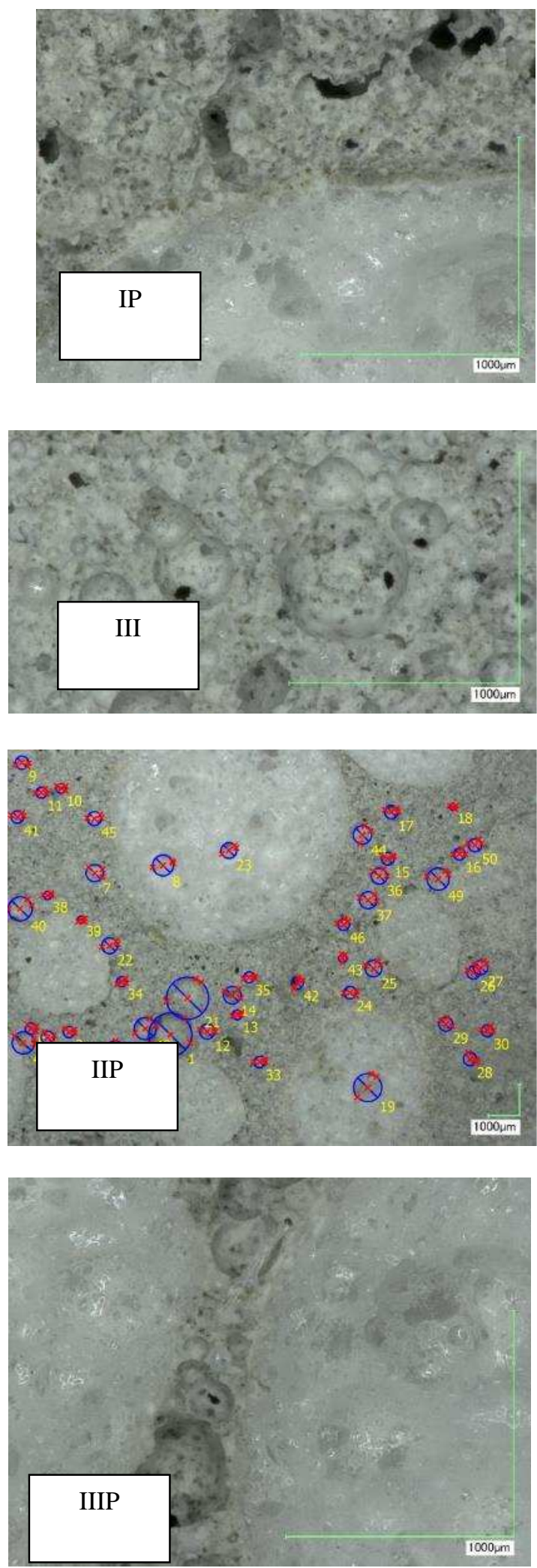

IIIP FC composition can be explained by adding superplasticizer. As it can been seen in Table 5, the diameter of pores reduces by adding porous 
Environment. Technology. Resources, Rezekne, Latvia Proceedings of the $11^{\text {th }}$ International Scientific and Practical Conference. Volume III, 222-228

aggregates, except of composition of FC mix with IIIP. This phenomenon can be explained by the use of superplasticizer.

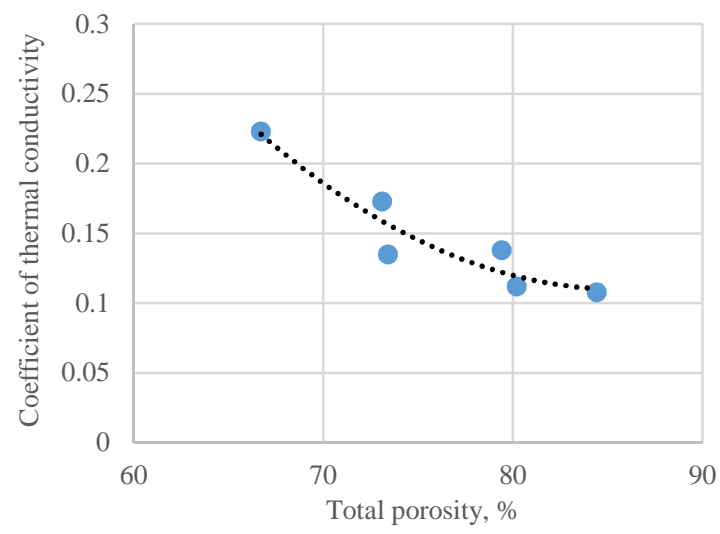

Fig. 7. Correlation between total porosity and thermal conductivity.

\section{CONCLUSIONS}

FC is widely used in the construction industry; the porous structure of FC can be obtained without heat treatment which is required for production of autoclaved aerated concrete.

Value of thermal conductivity can be reduced up to $0.108 \mathrm{~W} / \mathrm{mK}$ by using porous and lightweight aggregates in the production of FC.

Values of compressive strength increased using a superplasticiser. Also the use of cenospheres increased the compressive strength about $60 \%$ and $44 \%$.. Thereby for the FC with similar density the properties of mechanical strength were improved.

Reference compositions (I, II, and III) had lower values of weight loss $\left(\mathrm{g} / \mathrm{m}^{2}\right)$ after freeze-thaw test comparing to compositions with porous aggregate.

In the future studies it would be necessary to obtain more complete correlation between density and thermal conductivity of the FC. Therefore more detailed study of the pore size distribution and their impact on thermal conductivity of FC would be necessary.

\section{ACKNOWLEDGMENTS}

The financial support of European Regional Development Fund project Nr.1.1.1.1/16/A/007 "A New Concept for Sustainable and Nearly Zero-Energy Buildings" is acknowledged.

\section{REFERENCES}

11] P. Chastas, T. Theodosiou, and D. Bikas, "Embodied energy in residential buildings-towards the nearly zero energy building : A literature review," Build. Environ., vol. 105, pp. 267-282, 2016.

[2] M. A. O. Mydin, "Effective thermal conductivity of foamcrete of different densities," Concr. Res. Lett., vol. 2, no. March, pp. 181-189, 2011.

[3] D. Bajare, G. Bumanis, and A. Korjakins, "New Porous Material Made from Industrial and Municipal Waste for Building Application,” vol. 20, no. 3, pp. 3-8, 2014.

[4] V. Vaganov, M. Popov, A. Korjakins, and G. Šahmenko, "Effect of CNT on Microstructure and Minearological Composition of Lightweight Concrete with Granulated Foam Glass," Procedia Eng., vol. 172, pp. 1204-1211, 2017.

[5] E. Namsone, G. Sahmenko, and A. Korjakins, "Durability Properties of High Performance Foamed Concrete," Procedia Eng., vol. 172, pp. 760-767, 2017.

[6] N. Karagiannis, M. Karoglou, A. Bakolas, M. Krokida, and A. Moropoulou, "Drying kinetics of building materials capillary moisture," Constr. Build. Mater., vol. 137, pp. 441-449, 2017.

[7] U. Sharma, A. Khatri, and A. Kanoungo, "Use of micro-silica as additive to concrete-state of art," Res. India Publ., vol. 5, no. 1, pp. 9-12, 2014.

[8] J. T. Ding and Z. Li, "Effects of metakaolin and silica fume on properties of concrete," ACI Mater. J., vol. 99, no. 4, pp. 393-398, 2002

[9] B. Sabir, S. Wild, and J. Bai, "Metakaolin and calcined clays as pozzolans for concrete: A review," Cem. Concr. Compos., vol. 23, no. 6, pp. 441-454, 2001.

[10] S. Sen, "Physical Properties of CENOSPHERE," 2014.

[11] "FOX 600 and FOX 800 Series Instruments Manual. - Laser Comp, Inc." p. 32, 2001.

[12] M. . Khan, "Factors affecting the thermal properties of concrete and applicability of its prediction models," Build. Environ., vol. 37, no. 6, pp. 607-614, 2002.

[13] U. Schnider, Behavior of concrete at high temperatures. 1982.

[14] I. Örüng, "A research on usage possibilities of ground lightweight aggregate in agricultural buildings," no. Turkey 26, pp. 90-111, 1996.

[15] J. Setina, A. Gabrene, and I. Juhnevica, "Effect of pozzolanic additives on structure and chemical durability of concrete," Procedia Eng., vol. 57, pp. 1005-1012, 2013.

[16] 213R-03, Guide for Structural Lightweight-Aggregate Concrete, American Concrete Institute. ACI, 2003. 